\title{
Factores relacionados con la deserción en el primer y segundo año de estudio en la carrera de Enseñanza de la Matemática de la Universidad Nacional de Costa Rica
}

\author{
Factors Related to Dropping Out in the Freshman and Sophomore Years in the Career of \\ Teaching Mathematics at Universidad Nacional de Costa Rica

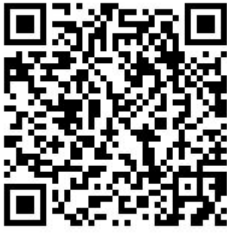 \\ Paola Michelle Pascua-Cantarero' \\ Universidad Católica de Honduras \\ Facultad de Ingeniería Industrial \\ Tegucigalpa, Honduras \\ paomich1@gmail.com
}

Recibido 21 de mayo de 2014 • Corregido 15 de setiembre de 2015 • Aceptado 3 de noviembre de 2015

\begin{abstract}
Resumen. El presente artículo da a conocer detalles sobresalientes obtenidos al realizar una investigación que tuvo entre sus objetivos determinar los factores relacionados con deserción de estudiantes, quienes ingresaron en los años 2007, 2008, 2009, durante el primer y segundo año del Bachillerato y Licenciatura en Enseñanza de la Matemática (carrera de Enseñanza de la Matemática) de la Universidad Nacional de Costa Rica. La citada investigación respondió a un estudio mixto, con una fase cuantitativa de carácter descriptivo y una parte cualitativa con un diseño fenomenológico; su fundamentación teórica se basó en investigaciones sobre deserción universitaria en distintas regiones y la teoría de personas expertas como Tinto y Spady con respecto a las causas de esta problemática. Para el análisis de la información se empleó una base de datos proporcionada por el Departamento de Registro de la UNA y una entrevista telefónica semi-estructurada aplicada a estudiantes que desertaron de la carrera en forma definitiva. La población en la fase cuantitativa estuvo constituida por la totalidad de participantes que ingresaron en los años 2007, 2008 y 2009 y que desertaron en el primer y segundo año de la carrera. El grupo en estudio para la etapa cualitativa estuvo compuesto por quince informantes pertenecientes a las diferentes cohortes 2007, 2008 y 2009 y quienes desertaron en el primer y segundo año de la carrera. Los resultados mostraron que el fenómeno de deserción en el primer año tuvo factores similares a la que se produjo en el segundo año de la carrera de Enseñanza de la Matemática. Las conclusiones indican que entre los diversos factores relacionados con la deserción en el primer y segundo año de las cohortes 2007, 2008 y 2009 sobresalieron las expectativas no satisfechas y la falta de integración académica y social como factores comunes.
\end{abstract}

Palabras claves. Deserción estudiantil universitaria, análisis cuantitativo, análisis cualitativo, matemáticas.

\footnotetext{
${ }^{1}$ Ingeniera Industrial y Magíster en Educación con Énfasis en Docencia Universitaria de la Universidad de Costa Rica. Ejerció por cuatro años como ingeniera planificadora en la Comisión Nacional de Telecomunicaciones de Honduras (CONATEL). Durante nueve meses fue docente de Matemática Didáctica en la Universidad Pedagógica Nacional de Honduras y actualmente es docente en la Facultad de Ingeniería Industrial de la Universidad Católica de Honduras y líder de proyectos en la red nacional de voluntariado de las Naciones Unidas en Honduras (UNV).
} 
doi: http://dx.doi.org/10.15359/ree.20-1.5

URL: http://www.una.ac.cr/educare

CORREO: educare@una.cr

\begin{abstract}
This article announces outstanding details obtained through the investigation carried out, which among its objectives were to determine the factors related to student drop out during the freshman and sophomore years of higher education and bachelor's degree in teaching mathematics (career of teaching mathematics) at National University of Costa Rica for those entering in 2007, 2008 and 2009. The mentioned research responded to a joint study, with a quantitative phase of descriptive character and a qualitative phase with a phenomenological design; its theoretical foundation was based on research on university dropout in different regions and the theory of Tinto and Spady experts regarding the causes for this problem. A database provided by the Registration Department of the National University of Costa Rica and a telephone semi-structured interviewed applied to students who defected from the major, in a final way, was used for the analysis of the information. The population in the quantitative phase was constituted by all participants who entered in the years 2007, 2008 and 2009 and dropped out in the first and second year of the career. The study group in the qualitative phase was composed by 15 informers belonging to the different cohorts 2007, 2008 and 2009 and who dropping out during the first and second year of the career. Results showed that the dropout phenomenon in the first year had similar factors as those occurred in the second year of the career of teaching mathematics. The conclusions indicate, among several factors related to dropping out in the first and second year of the 2007, 2008 and 2009 cohorts, that unmet expectations and lack of academic and social integration stand out as common factors.
\end{abstract}

Keywords. College dropouts, quantitative research, qualitative research, mathematics.

La deserción estudiantil universitaria suele ser un fenómeno que enfrentan todas las instituciones de educación superior ubicadas en diferentes latitudes, enormes cantidades de estudiantes se matriculan para diversas carreras; sin embargo, en diferentes momentos de esas disciplinas y por diversas razones, gran cantidad decide no continuar con los estudios escogidos $y$, en el peor de los casos, desertan definitivamente del sistema de educación superior, por lo cual pierden una valiosa oportunidad en cuanto a su realización personal.

El sistema de educación superior costarricense no escapa a la problemática de deserción estudiantil, razón por la cual el denominado Fondo de Financiamiento de la Educación Superior (FEES) en conjunto con Comisión Nacional de Rectores (CONARE) y el Sistema Nacional de Acreditación de la Educación Superior (SINAES) se propusieron, entre otros objetivos, invertir en asuntos relacionados con la permanencia y graduación de estudiantes en las cuatro universidades estatales del país (Programa Estado de la Nación, 2013). Con respecto a estos proyectos, en la investigación sobre deserción, Brenes (2005) concluye que el abandono de los estudios en las universidades estatales de Costa Rica está vinculado con varios factores, los cuales van desde aquellos relacionados con el estudiantado y otros que apuntan al personal docente académico.

La importancia de estudiar los factores particulares que inciden en el fenómeno de deserción estudiantil radica no solo en, tal y como afirma Castillo (2008), el alto costo de la educación, lo cual hace que valga la pena tomar medidas para retener a aquel estudiantado 
doi: http://dx.doi.org/10.15359/ree.20-1.5

que ya hubiera avanzado a un nivel superior luego de concluir la educación secundaria, sino también en que, por medio de la ubicación de las factores incidentes en esta problemática, se pueden plantear estrategias dirigidas a mejorar no solo la cobertura educativa sino también la calidad de dicha enseñanza.

En el caso de la carrera de Enseñanza de la Matemática de la Universidad Nacional de Costa Rica (UNA), como suele ocurrir con otras disciplinas donde están involucradas las ciencias exactas, la deserción estudiantil suele ser característica de estas y amerita procesos investigativos que proporcionen una visión holística de los factores involucrados en este fenómeno.

Es usual que el tema sobre el abandono de los estudios por parte de estudiantes sea abordado desde perspectivas meramente cuantitativas que si bien proporcionan importantes datos estadísticos e interpretaciones de estos datos, en su mayoría, dejan de lado valiosa información que puede estar contenida en aspectos más profundos sobre los cuales las estrategias de investigación cualitativa proporcionan metodologías muy provechosas.

Este artículo se basa en una investigación sobre factores relacionados con la deserción estudiantil universitaria que reviste un carácter mixto durante la cual, inicialmente, se hizo uso del paradigma positivista para realizar importantes cálculos estadísticos y enriquecerlos posteriormente mediante la indagación e interpretación cualitativa de otros de datos.

\section{Algunos antecedentes acerca de investigaciones sobre la deserción universitaria}

Uno de los primeros estudios sobre deserción universitaria documentados y que forma parte de cualquier investigación sobre el tema, es el modelo de análisis que propone Spady (1970). El autor utiliza la teoría del suicidio de Durkheim (1897) para relacionar el abandono de los estudios por parte de estudiantes con la falta de deseo por continuar inmerso en una determinada comunidad interpretando así ambos fenómenos, el suicidio y la deserción, como una especie de renuncia a un sistema social.

Spady (1970) enfatiza la importancia de la armonía entre aspectos como los antecedentes del estudiantado y su nuevo ambiente escolar por lo cual introduce el concepto de "congruencia normativa" (p. 39) para referirse a esta interacción (ver figura 1). El mencionado autor concluye que el éxito para terminar una carrera depende de la capacidad de integración en el sistema social y universitario, y el poder cumplir las demandas de ambos.

Posterior al estudio sobre deserción de Spady (1970) y retomando ciertos aspectos de su modelo de análisis, Tinto (1993) aparece como uno de los teóricos más conocidos y quien, probablemente, ha estudiado de manera más prolongada el fenómeno. 
doi: http://dx.doi.org/10.15359/ree.20-1.5

URL: http://www.una.ac.cr/educare

CORREO: educare@una.cr

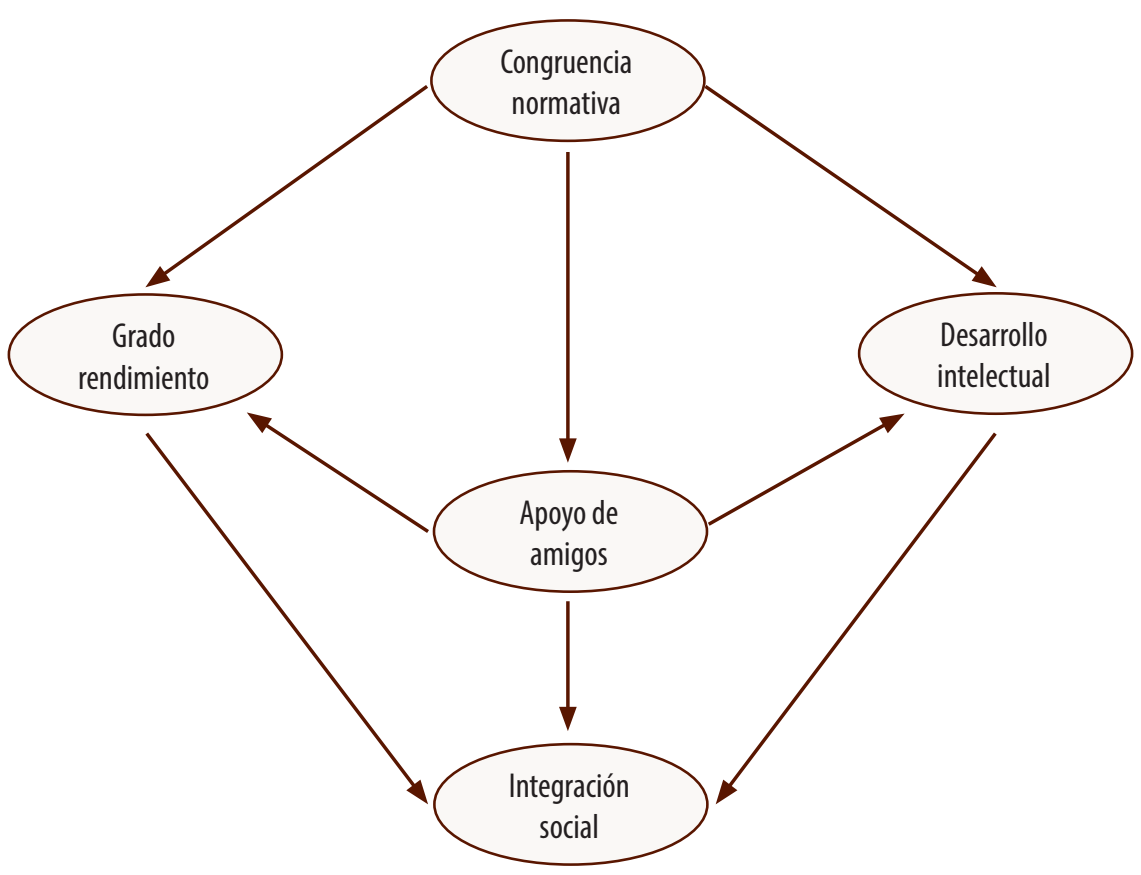

Figura 1. Factores relacionados con la congruencia normativa. Elaboración propia, a partir del modelo de análisis de la deserción en educación superior de Spady (1970, p. 39).

Tinto (1993) realiza una investigación de carácter mixto sobre las causas que inciden en la deserción y propone un modelo de análisis así como y, más importante aún, sugerencias estratégicas de solución a la problemática.

Tinto (1993), al igual que Spady (1970), retoma inicialmente el concepto de Durkheim (1897); pero no ahonda demasiado en este. Su estudio comienza con un significativo análisis estadístico para luego continuar con una exhaustiva interpretación cualitativa.

Tinto (1993) diseña su modelo de análisis para la deserción estudiantil y lo basa en las cinco etapas por las cuales, según él, pasa cada estudiante antes de decidir abandonar sus estudios. En la primera de esas etapas, indaga sobre sus antecedentes familiares y habilidades. En la segunda etapa aborda temas relacionados con las metas del estudiante o la estudiante, con lo cual introduce importantes conceptos como "la incertidumbre de las intenciones" y el "compromiso académico". Durante la tercera etapa, Tinto (1993) analiza las experiencias estudiantiles dentro de la institución. Para llevar a cabo el análisis de la cuarta etapa se enfoca en indagar acerca de su "integración académica y social"y durante la quinta etapa, el autor propone que se reanalicen las intenciones y compromiso académico del estudiante participante para determinar si este ha cambiado con respecto al inicial (ver figura 2). 
doi: http://dx.doi.org/10.15359/ree.20-1.5

URL: http://www.una.ac.cr/educare

CORREO: educare@una.cr

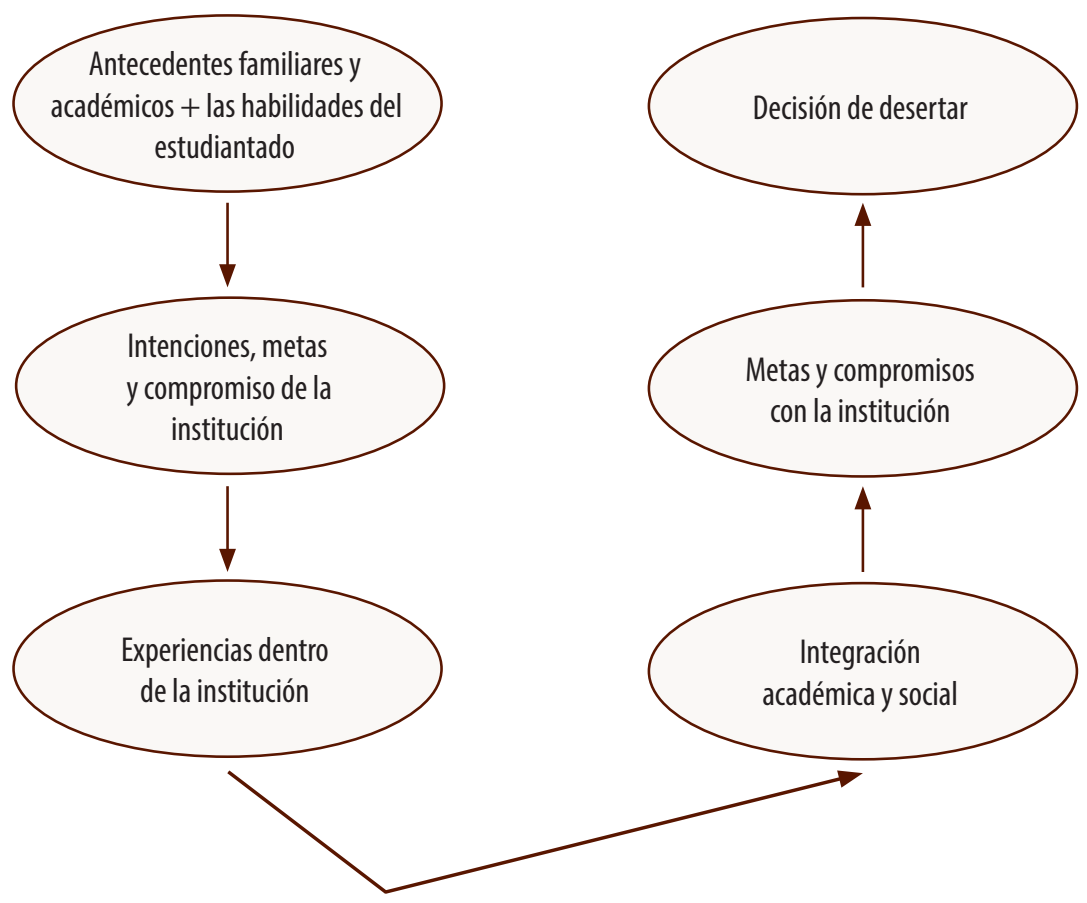

Figura 2. Factores relacionados con la deserción estudiantil universitaria. Elaboración propia a partir de Tinto (1993).

Además de los modelos explicativos de la deserción propuestos por Spady (1970) y Tinto (1993), existen otros estudios que sugieren diferentes formas de análisis para dicha problemática. Algunos de estos modelos se enfocan en aspectos relacionados con la conducta del estudiantado en respuesta a ciertos eventos, por ejemplo, Fishbein y Ajzen (1975) proponen "la teoría de la acción razonada", Ethington (1990) plantea el análisis de la "conducta del logro" y, por su parte, Pascarella y Terenzini (1991) al igual que Tinto (1993) analizan la poderosa influencia de la integración académica.

En América Latina, diversos estudios han tomado las ideas de los teóricos mencionados anteriormente sobre todo de Spady (1970) y Tinto (1993) para realizar adaptaciones a sus investigaciones, tal fue el caso de Saldaña y Barriga (2010), los cuales realizaron una adaptación del modelo de Tinto (1993) por medio de una investigación de carácter cuantitativo sobre la deserción en la carrera de Ingeniería Civil en la Universidad Católica de la Santísima Concepción en Chile. Los autores concluyen cuando el estudiantado se encuentra inmerso en la universidad, los factores que más inciden en la deserción son el promedio semestral, la cantidad de clases aprobadas y la forma de financiar la continuación de sus estudios. 
doi: http://dx.doi.org/10.15359/ree.20-1.5

URL: http://www.una.ac.cr/educare

CORREO: educare@una.cr

En Argentina en la Universidad del Litoral, Walz, Contini, Bergesio y Colombini (2009), durante la realización de una investigación cuantitativa, indagan sobre los factores académicos que inciden en la deserción universitaria en la carrera de Biología. La investigación pretendió analizar los efectos de un curso de Matemática en el primer semestre de estudio.

Walz et al. (2009) concluyeron que el curso de Matemática inserto en el primer semestre de la carrera de Biología fue una de las causas que incidió en la deserción, pues en ese periodo el estudiantado aún no había asimilado su inclusión a la vida universitaria.

Por su parte, Lopera (2008), en la Universidad del Rosario, Colombia, en su estudio cuantitativo analiza la deserción durante el primer y segundo semestre en la Facultad de Economía, concluyendo que el abandono de los estudios es consecuencia del bajo rendimiento y el rezago en algunas materias.

\section{Estudios cualitativos y mixtos sobre deserción}

Como se mencionó con anterioridad, las diversas investigaciones sobre deserción universitaria suelen ser cuantitativas, por esta razón este artículo rescata algunos de los importantes estudios de carácter cualitativo y mixto que se han llevado a cabo en distintos países de América Latina. De este modo se tienen las investigaciones de Canales y de los Ríos (2007), Lagger, Donnet, Gimenez y Samoluk (2008), Pineda y Pedraza (2009) y Mori (2012).

En el caso de Canales y de los Ríos (2007), los autores realizaron una investigación cualitativa mediante una metodología exploratoria con la que indagaron la relación con los tipos de deserción temporal y permanente en cuatro universidades privadas y cinco públicas del sistema de educación superior chileno.

Además de enfocarse en los desertores temporales y permanentes, se centraron en analizar los factores académicos y extraacadémicos que influyen en la deserción estudiantil, con lo cual Canales y de los Ríos (2007) llegan a importantes conclusiones, una de estas es el hecho de que la deserción temporal y la permanente son fenómenos distintos, así como las causas que las provocan. Sin embargo, en ambos tipos de deserción, "las razones no académicas juegan un rol muy relevante" (p. 184).

En Argentina Lagger et al. (2008) analizaron la deserción del estudiantado de la carrera de Ingeniería Industrial y concluyen que el no aprobar clases como Análisis Matemático, Álgebra, Física, Química y la dificultad para entender la explicación del maestro o maestra así como la disponibilidad del tiempo y otros, fueron los factores que incidieron en la deserción de estudiantes.

De nuevo en Argentina, Pineda y Pedraza (2009), mediante una metodología fenomenológica, indagaron en varias carreras a fin de analizar las experiencias del estudiantado 
que hicieron que programas de estrategias de retención tuvieran éxito. Concluyeron que los programas exitosos fueron aquellos centrados en las "transformaciones al interior del individuo y además fortalecieron sus posibilidades de integración académica y social” (p. 27).

Y por último, en Perú, la investigación cualitativa realizada por Mori (2012) sobre las causas de deserción en una universidad privada de lquitos, concluyó, entre otros aspectos que "la decisión de desertar radica en la falta de vínculos con los objetivos y metas personales propuestas al elegir la carrera" (p. 73).

\section{En lo concerniente a la carrera de Enseñanza de la Matemática}

El estudio sobre graduación y deserción realizado por Chaves (2003) brinda importantes luces sobre el comportamiento de ambos fenómenos en la carrera de Enseñanza de la Matemática. El autor concluye que la deserción estudiantil se debe primordialmente al bajo rendimiento en los cursos sobre todo en el primer año y con respecto a lo cual recomienda tomar medidas relacionadas no solo con los cursos problemáticos sino con el proceso de selección del estudiantado, pues Chaves (2003) afirma que una gran cantidad de jóvenes que ingresan a la carrera no tienen la preparación para dicha carrera.

En un intento por enfrentar la problemática sobre deserción, la Escuela de Matemática inicio en 2008 una modificación a la malla curricular de la carrera de Enseñanza de la Matemática, la cual consistió en trasladar de periodo ciertos cursos que eran considerados como filtro, de esta forma la materia de Geometría Euclídea I, la cual se encontraba en el primer ciclo del primer año, se trasladó al segundo ciclo del mismo año el curso de Geometría Euclídea II se desplazó al primer ciclo del segundo año y el curso de Lógica y Teoría de Conjuntos, al primer ciclo del primer nivel (Escuela de Matemática, UNA, Costa Rica (Acta No. 15, 2007). Con estas y otras medidas, la Escuela de Matemática estableció, en su Informe de ejecutoria (2007-2008), uno de los propósitos el reducir la deserción en un $10 \%$.

\section{El término de deserción}

Este término a menudo es relacionado con el fracaso del estudiantado en terminar un determinado plan de estudios, o con el bajo rendimiento en los cursos. Sin embargo, tal definición resulta apresurada si no se han tomado en cuenta otros aspectos. Al respecto, Tinto (1989) hace una importantísima reflexión sobre el término, el autor afirma que poder definir la deserción depende del enfoque que se tenga, el cual puede ser individual (refiriéndose al estudiantado) o institucional, por lo tanto, aunque para la universidad la deserción sea vista como fracaso estudiantil en terminar una disciplina, el estudiantado puede percibirla como un evento favorable que lo acerca más a sus metas. 
doi: http://dx.doi.org/10.15359/ree.20-1.5

URL: http://www.una.ac.cr/educare

CORREO: educare@una.cr

Por lo que, a manera de propuesta, si se tuviera que establecer un término más idóneo, la deserción universitaria podría definirse como el abandono de los estudios sin haber sino concluidos, el cual, con base en las experiencias e intenciones del estudiantado, puede convertirse en fracaso escolar o en una transición hacia sus verdaderos objetivos recién o tardíamente descubiertos.

\section{Los varios tipos de deserción}

Otro aspecto importante por analizar es la tipología de la deserción estudiantil. Ciertos autores identifican varios tipos de deserción, para algunos es importante definirla según el momento cuando ocurrió el abandono de los estudios, así Guzmán et al. (2009) identifican un tipo de deserción precoz el cual ocurre antes de iniciar las clases. Por su parte, Lopera (2008) distingue la deserción temprana y tardía, según esta autora, la deserción temprana acontece en los primeros cuatro semestres de haber iniciado las clases y lo que ella llama deserción tardía se produce a partir del segundo año de estudios.

Himmel (2005) considera importante tomar en cuenta si la deserción fue voluntaria o involuntaria, es decir, si fue decisión propia del estudiantado retirarse de la carrera o tal acción fue causada por la institución.

Otros investigadores como Canales y de los Ríos (2007) y Tinto (1993) identifican los tipos de deserción temporal y definitiva. En el primer caso Canales y de los Ríos (2007) explican que es cuando el estudiante ha desertado al menos una vez de alguna carrera, pero regresa al sistema de educación para continuar con la carrera que había abandonado o escoge otra disciplina.

En el caso de la deserción definitiva, la definición debe ser más precisa, pues el abandono puede remitir a la carrera o. como afirma Tinto (1993), al sistema de educación superior. Para este artículo en particular, la deserción definitiva remite al abandono especifico de la carrera escogida, dejando abierta la posibilidad de que el educando se encuentre estudiando otra disciplina en la misma institución o en otra diferente.

\section{La carrera de Enseñanza de la Matemática}

La carrera de Enseñanza de la Matemática es una disciplina compartida por dos unidades académicas: la División de Educologia y la Escuela de Matemática, ambas pertenecientes a la UNA, cada una de estas instancias hace un importante aporte de contenidos complementarios. Por su parte, Educologia es la encargada de impartir el componente pedagógico de la carrera y la Escuela de Matemática de aportar el contenido matemático.

Actualmente la mencionada disciplina se encuentra en un proceso de reacreditación, lo que exige la investigación acerca de aquellos aspectos que se presentan como debilidades, en este caso la recurrente deserción estudiantil. 
doi: http://dx.doi.org/10.15359/ree.20-1.5

URL: http://www.una.ac.cr/educare

CORREO: educare@una.cr

\section{Metodología utilizada}

Este artículo se basa en una investigación de carácter mixto, con una fase inicial cuantitativa meramente descriptiva y una segunda parte cualitativa de tipo fenomenológico.

Al respecto, Hernández, Fernández y Baptista (2010) indican que los estudios descriptivos son aquellos que"únicamente pretenden medir o recoger información de manera independiente o conjunta sobre los conceptos y las variables a las que se refieren, esto es, su objetivo no indicar como se relacionan [estas]" (p. 80).

Por su parte, Mertens (2005, citado por Hernández, Fernández y Baptista, 2010) considera que el esquema fenomenológico en investigación se centra en la experiencia y significado individual de los entes participantes respecto a un fenómeno en particular. Mertens (2005, citado por Hernández, Fernández y Baptista, 2010) plantea como característica importante de estudios fenomenológicos el análisis de discurso de sus participantes, enfocado en temas específicos para luego otorgarles un significado. Tal cual se hizo en la investigación en la que se basa el presente artículo. Sumado a esto, en concordancia con lo planteado por Hernández, Fernández y Baptista (2010), el presente estudio contextualizó los hechos en el momento en que ocurrieron y a las personas que experimentaron el fenómeno. Es decir, estudiantes de la carrera de Matemática que desertaron.

Debido a que la investigación se propuso determinar los factores que incidieron en la deserción en el primer y segundo año de la carrera para las cohortes 2007, 2008 y 2009, la población total del estudio estuvo constituida por estudiantes que desertaron en el primer año y quienes se marcharon en el segundo año de la carrera, estudiándose, de este modo, dos grupos por cohorte, por lo cual se tuvo un total de seis poblaciones que entre todas sumaron 66 estudiantes (ver tabla 1).

Tabla 1

Estudiantes que desertaron en el primer y segundo año distribuidos en cada una de las cohortes en estudio

\begin{tabular}{|c|c|c|c|c|c|c|}
\hline Cohorte & \multicolumn{2}{|c|}{2007} & \multicolumn{2}{|c|}{2008} & \multicolumn{2}{|c|}{2009} \\
\hline Año & Primero & Segundo & Primero & Segundo & Primero & Segundo \\
\hline Cantidad de estudiantes & 24 & 8 & 11 & 2 & 12 & 9 \\
\hline Total por año & \multicolumn{2}{|c|}{32} & \multicolumn{2}{|c|}{13} & \multicolumn{2}{|c|}{21} \\
\hline
\end{tabular}

Total de estudiantes que desertaron respecto a todas las cohortes $=66$

Nota: Elaboración propia con base en datos proporcionados por el Departamento de Registro sobre la deserción en la carrera de Enseñanza de la Matemática de la Universidad Nacional, Costa Rica. 
doi: http://dx.doi.org/10.15359/ree.20-1.5

URL: http://www.una.ac.cr/educare

CORREO: educare@una.cr

En la primera fase, la cuantitativa, se determinaron índices de deserción para cada uno de los dos grupos por generación, es decir, los porcentajes de deserción en el primer y segundo año para cada una las cohortes 2007, 2008 y 2009. Así como importantes índices de deserción relacionados con el sexo de los participantes. Estos cálculos se realizaron utilizando información proporcionada por el Departamento de Registro sobre el comportamiento de la matricula por año en la carrera de Enseñanza de la Matemática.

En la segunda fase, la cualitativa de tipo fenomenológico, se utilizó como instrumento una entrevista telefónica semiestructurada, la cual fue aplicada a exestudiantes de la carrera de Enseñanza de la Matemática pertenecientes a las cohortes 2007, 2008 y 2009 y que se marcharon en su primer año de estudio y quienes se fueron en el segundo año con el objetivo de analizar el discurso de estos mismos. Esta vez la muestra, por ser cualitativa, fue denominada grupo en estudio y fue constituida por quince participantes que se localizaron vía teléfono y accedieron a realizar la entrevista, por lo que se considera una muestra por conveniencia.

\section{El tipo de deserción de interés}

La investigación en la cual se basa este artículo se interesó por un tipo de deserción definitiva de la disciplina, en este caso la carrera de Enseñanza de la Matemática de la UNA, por lo que aquellas personas participantes catalogadas como desertoras temporales o reincidentes no fueron tomadas en cuenta.

Es importante resaltar que para denominar a estudiantes como desertores definitivos algunos autores, como Chaves (2003), estipulan que debe tener como mínimo dos años de haberse retirado de la carrera, por su parte el Departamento de Registro establece que debe ser después de cinco años de ausencia desde su primera matricula cuando un estudiante puede denominarse como desertor o desertora. Para efectos del estudio se consideró como desertora o desertor definitivo de la carrera de Enseñanza de la Matemática a aquel estudiantado que desde su retiro de la disciplina no presentó matrícula hasta 2012.

\section{Variables y categorías}

En la primera fase cuantitativa se utilizaron las siguientes variables:

- El sexo de participantes: Esta variable remite al género de participantes

- El tipo de deserción definitiva de la carrera.

- El comportamiento del proceso de matrícula de estudiantes 
doi: http://dx.doi.org/10.15359/ree.20-1.5

Las categorías utilizadas en la parte cualitativa del estudio fueron las que se exponen en la tabla 2:

Tabla 2

Matriz de categorías y subcategorías

\begin{tabular}{|c|c|c|c|}
\hline $\begin{array}{l}\text { Factores } \\
\text { socioeconómicos }\end{array}$ & $\begin{array}{l}\text { Factores } \\
\text { individuales }\end{array}$ & $\begin{array}{l}\text { Factores } \\
\text { institucionales }\end{array}$ & $\begin{array}{l}\text { Factores } \\
\text { académicos }\end{array}$ \\
\hline Percepción económica & Situaciones de calamidad & $\begin{array}{l}\text { Dificultades con alguna } \\
\text { materia particular }\end{array}$ & Métodos de estudio \\
\hline Entorno familiar & Situaciones domésticas & $\begin{array}{l}\text { Apoyo por parte de la } \\
\text { institución }\end{array}$ & Hábitos de estudio \\
\hline Estado civil & $\begin{array}{l}\text { Expectativas no } \\
\text { satisfechas }\end{array}$ & $\begin{array}{l}\text { Disponibilidad de los } \\
\text { cursos }\end{array}$ & $\begin{array}{l}\text { Percepción de } \\
\text { rendimiento }\end{array}$ \\
\hline Lugar de residencia & Vocación de estudio & & Integración académica \\
\hline Estímulos & Integración social & & \\
\hline Tipo de trabajo & $\begin{array}{l}\text { Percepción de } \\
\text { la causa } \\
\text { principal }\end{array}$ & & $\begin{array}{l}\text { Motivación académica } \\
\text { inicial }\end{array}$ \\
\hline $\begin{array}{l}\text { Disponibilidad de } \\
\text { tiempo por trabajo }\end{array}$ & & & \\
\hline
\end{tabular}

Nota: Elaboración propia.

\section{Resultados de la investigación}

En lo que respecta a la primera etapa cuantitativa de la investigación, este articulo expone la similitud de esta con el estudio anterior realizado por Chaves (2003) en lo referente a los porcentajes de deserción y a los índices según la variable del sexo de sus participantes.

\section{Fase cuantitativa}

Si se analiza por cohorte, se observa que en la generación de 2007 y la de 2009 la deserción en el primer y segundo año representa más del 50\% del estudiantado que ingresó a la carrera (ver tabla 3). 
doi: http://dx.doi.org/10.15359/ree.20-1.5

URL: http://www.una.ac.cr/educare

CORREO: educare@una.cr

Tabla 3

Índices de deserción en el primer y segundo año de la carrera

\begin{tabular}{lcccc}
\hline \multirow{2}{*}{ Año } & \multicolumn{4}{c}{ Cohorte } \\
\cline { 2 - 5 } & 2007 & 2008 & 2009 & Promedio \\
\hline Primer año & $39.34 \%$ & $33.33 \%$ & $30.00 \%$ & $34.23 \%$ \\
Segundo año & $13.11 \%$ & $6.06 \%$ & $22.50 \%$ & $13.89 \%$ \\
\hline Total & $52.46 \%$ & $39.39 \%$ & $52.50 \%$ & $48.12 \%$ \\
\hline
\end{tabular}

Nota: Elaboración propia a apartir de datos proporcionados por el Departamento de Registro de la UNA.

Al comparar estos resultados con el estudio anterior de Chaves (2003) sobre deserción y graduación en la carrera respecto a cohortes de 1995, 1996, 1997 y 1998, en el cual el autor expone que el promedio de la deserción en el primer y segundo año corresponde a un 52.8\%. Se determina que el fenómeno ha disminuido en menos de un $5 \%$. Sin embargo, si se analizan los índices por aparte la deserción en el segundo año se mantiene, pues Chaves (2003) establece un índice del $13.2 \%$, el que es casi igual al mostrado en la tabla 3.

Lo anterior llevo a analizar el comportamiento de la matrícula y la deserción según el sexo de sus participantes (ver tabla 4).

De acuerdo con los porcentajes, la mayor cantidad de matrícula en las cohortes 2007 y 2008 estuvo compuesta por hombres no así en la cohorte 2009 en la cual el mayor índice de matrícula lo tienen las mujeres.

Tabla 4

Índices de matrícula según el sexo de sus participantes

\begin{tabular}{lccc}
\hline & \multicolumn{3}{c}{ Cohortes } \\
\hline Sexo de los participantes & 2007 & 2008 & 2009 \\
\hline Hombres & $57.38 \%$ & $54.55 \%$ & $47.50 \%$ \\
Mujeres & $42.62 \%$ & $45.45 \%$ & $52.50 \%$ \\
\hline Total matrícula & $100.00 \%$ & $100.00 \%$ & $100.00 \%$ \\
\hline
\end{tabular}

Nota: Elaboración propia a partir de los datos proporcionados por el Departamento de Registro de la UNA. 
Al comparar estos porcentajes de matrícula con los de deserción según el sexo, se determinó que dicha variable en lo que respecta a la cohorte 2009 no pareció definir los índices de deserción, pues en esta cohorte los hombres continuaron siendo los mayores desertores, pese a que se matricularon más mujeres como se muestra en la tabla 5. Este aspecto concuerda con el estudio de Chaves (2003), el cual explica también que "los varones tienden a desertar en mayor medida" (p. 118).

Tabla 5

Índices de deserción según el sexo de los participantes

\begin{tabular}{lcccc}
\hline \multicolumn{5}{c}{ Cohortes } \\
\hline Sexo de los participantes & 2007 & 2008 & 2009 & Promedio \\
\hline Hombres & $66 \%$ & $54 \%$ & $52 \%$ & $53.33 \%$ \\
Mujeres & $34 \%$ & $46 \%$ & $48 \%$ & $42.66 \%$ \\
\hline Total matrícula & $100 \%$ & $100 \%$ & $100 \%$ & \\
\hline
\end{tabular}

Nota: Elaboración propia a partir de los datos proporcionados por el departamento de Registro de la UNA.

\section{Fase cualitativa}

Como se mencionó en la metodología, la información fue recolectada directamente del discurso de los participantes mediante la entrevista telefónica.

\section{¿Quiénes son los participantes?}

Antes de sumergirse en el análisis cualitativo de los resultados es inevitable preguntarse: ¿quiénes eran estos estudiantes?, ¿quiénes son en la actualidad?, pues esto de alguna manera reforzaría la idea de que vale la pena descubrir las debilidades para, con urgencia, plantear posibles soluciones.

Según el relato de participantes, la mayoría actualmente está por terminar una carrera y gran parte ya la ha finalizado, en especial quienes ingresaron a la Universidad en 2007.

Entre esas disciplinas estudiadas irónicamente se encuentra la carrera de Enseñanza de la Matemática, además de Ingeniería Eléctrica, Telemática, Contaduría y Finanzas, Secretariado Contable, Música, Derecho y algunas especialidades en Educación entre otras. 
doi: http://dx.doi.org/10.15359/ree.20-1.5

URL: http://www.una.ac.cr/educare

CORREO: educare@una.cr

Como se puede apreciar, sí hay carreras en las cuales las matemáticas siguieron formando parte de su diario vivir, por otro lado hubo otros grupos de estudiantes quienes, después de desertar optaron por las ciencias sociales. El punto es que: estudien o no una carrera técnica, las personas participantes mostraron interés por obtener un título universitario, este aspecto hace que valga la pena analizar sus respuestas sobre su experiencia mientras cursaban la carrera de Enseñanza de la Matemática en la UNA.

\section{La deserción durante el primer año}

Unificando los datos de las dos fases del estudio, la cuantitativa y la cualitativa, se determinó que los aspectos involucrados en el 39.34\% de deserción durante el primer año en la cohorte 2007 y el $30.00 \%$ de deserción en el primer año en la cohorte de 2009 fueron los factores académicos, individuales, institucionales y socioeconómicos, los cuales se profundizaran más adelante.

En el caso de la cohorte 2008, el porcentaje de deserción de 33.33\% en el primer año así como el porcentaje de deserción de $6.06 \%$ en el segundo año estuvo determinado por los mismos factores y en ese mismo orden, es decir, factores académicos, individuales, institucionales y socioeconómicos.

En todas las cohortes la causa más sobresaliente fue la desintegración académica, en otras palabras, la incapacidad del estudiantado para adaptarse al rigor académico de todos los cursos de la carrera de Enseñanza de la Matemática.

Pese a que la desintegración académica fue la causa más evidente de la deserción en el primer año, hubo otros factores subsiguientes que dividieron a los grupos de estudiantes quienes se marcharon en el transcurso del primer año, en dos grandes grupos: estudiantes cuya desintegración académica estuvo estrechamente relacionada con su poca vocación por los estudios escogidos y participantes cuya incapacidad de integrarse al rigor académico fue la suma de aspectos diferentes a la falta de vocación.

En este sentido, la investigación coincide con lo planteado por Tinto (1993) con respecto a las dos rutas que se deben seguir al analizar la deserción: el despido académico y el retiro voluntario. Tinto explica que cuando la deserción se produce por causas relacionadas con la vocación del estudiante, la deserción es más un aspecto voluntario, no así cuando el abandono es producto de elementos tanto individuales como aspectos que atañen a la institución para lo cual el autor define el concepto de despido académico.

El grupo de informantes que desertó en el primer año por causa de desintegración académica debida a su carencia de vocación, estuvo compuesto por algunos exestudiantes pertenecientes a las cohortes 2007 y 2009, y por todos los entrevistados de la cohorte 2008. 
En lo que respecta a este primer grupo de estudiantes carentes de vocación, en cuanto al porqué se matricularon para estudiar la carrera de Enseñanza de la Matemática sus respuestas revelan sus intenciones.

La verdad yo quería entrar a Ingeniería eléctrica en la UCR pero no me alcanzo el promedio, sí... entonces por convalidar materias quería ir adelantando pensé en llevar simplemente las matemáticas" (participante de cohorte 2008 I, graduado de Ingeniería Eléctrica).

¡Ehhh no tenía ehh digamos algo claro lo que quería ser, de ahí dije bueno dyy de ahí en adelante puedo hacer el trampolín a alguna otra carrera, pero diii al final no lo no, no lo concrete (participante de cohorte 2008 I, estudiante de Música).

El segundo grupo de participantes cuya desintegración académica fue producto de otros factores diferentes a la falta de vocación estuvo compuesto de exestudiantes pertenecientes a las cohortes 2007 y 2009. Este grupo de informantes, a diferencia de los anteriores, manifestó un interés particular por la carrera de Enseñanza de la Matemática con base en sus experiencias positivas con la materia cuando estudiaban en el colegio, además, expresaron que su meta inicial fue convertirse en profesores de Matemática.

Con respecto al grupo anterior, se evidenció que la desintegración académica estuvo antecedida y seguida por otros factores, lo cual hizo que fuera necesario analizar la ruta de forma independiente para cada cohorte.

\section{Deserción por desintegración académica en el primer año para la cohorte 2007}

En el caso de la cohorte 2007, los factores que incidieron en la deserción comenzaron con las expectativas no satisfechas, continuando con la desintegración social, es decir, su incapacidad de hacer grupos de trabajo y amistades dentro de la institución, lo cual provocó al estudiantado dificultades con el curso de Matemática Fundamental I, lo que indujo la desmotivación que a su vez originó la desintegración académica en relación con las demás materias cursadas en ese entonces y todo les llevo a tomar la decisión de desertar de la carrera de Enseñanza de la Matemática.

Un hecho curioso con respecto a este grupo fue que, el tener dificultades académicas con el curso de Matemática Fundamental I, condicionó el comportamiento relacionado con las demás materias cursadas en ese momento, posiblemente, debido a que perciben con especial importancia los cursos matemáticos, lo cual significa que tener problemas en uno de esos cursos es más importante que ser exitoso en los demás. 
doi: http://dx.doi.org/10.15359/ree.20-1.5

URL: http://www.una.ac.cr/educare

CORREO: educare@una.cr

\section{Deserción por desintegración académica en el primer año para la cohorte 2009}

Para lo que respecta a la cohorte 2009, los factores que incidieron en la deserción comenzaron con la falta de estímulos en el hogar, a los cuales les siguieron las expectativas no satisfechas de la carrera. Para cierta cantidad de estudiantes, el desempeñar un empleo cuando ingresaron a la carrera y mientras estuvieron cursándola les dificultó la integración social y académica. Sumado a estos aspectos, un grupo de informantes expresó que la actitud recriminadora por la parte docente en el aula provocó su desmotivación final por continuar en la carrera por lo que decidieron desertar.

\section{¿Cómo esperaba el estudiantado participante que fuera la carrera de Enseñanza de la Matemática?}

Debido a que las expectativas no satisfechas fueron un factor que sobresalió en la deserción de las cohortes 2007 y 2009, se hace necesario exponer las ideas preconcebidas que los grupos participantes tenían de la carrera.

Las respuestas de los informantes revelan que tales ideas, esperanzas o expectativas se referían al ambiente y el trato que recibirían.

Diay ii La verdad, la verdad como...como,.. talvez esperaba que..., como le explico, esperaba... un poquito más deee comprensión a alguien nuevo talvez, talvez.... eso esperaba (participante de cohorte 2007 I, estudiante de Telemática).

Ehh la esperaba bastante dura y de hecho eso fue lo que pasó, ehh quería como que, aunque también uno quiere como que... que los profesores no fueran tan groseros pero también estrictos (participante de cohorte 2009 I, estudiante de Secretariado Contable).

En lo que respecta a la desintegración social, la cual estuvo muy ligada a la desintegración académica, la cohorte 2007 remite directamente al ambiente en la Escuela de Matemática.

Eso... tal vez... fue una de las cosas que me motivó a, ... a dejarla talvez...., porque talvez, bueno, los cursos que yo matriculé, talvez había gente que ya la había llevado, entonces era como, un poquillo, el ambiente era un poquillo incómodo para alguien nuevo porque talvez yo llegaba y habían cosas que se veían muy rápido ooo algo así, ya ellos se entendían, ellos sabían más y el problema mío fue más que todo eso, ósea yo llegaba a clases y talvez veían la materia muy rápido y tampoco tenía mucha confianza para preguntarle a alguien, el ambiente era un poquillo pesado talvez (participante de cohorte 2007 I, estudiante de Telemática). 
En lo referente a la dificultad con algún curso en particular, algunos participantes pertenecientes a la cohorte 2009 hicieron referencia a la conducta de censura por parte del profesorado en la Escuela de Matemática.

... Es que tuve dos profesores y digamos uno de esos profesores fue muy grosero tanto que pues... como (silencio) que no ... El profesor era muy grosero era así como que ... usted no sirve para nada (risa). (Participante de cohorte 2009 I, estudiante de Secretariado Contable).

Respecto a La deserción en el primer año en las cohortes 2007 y 2009, se puede apreciar una clara referencia hacia factores que involucran a la Escuela de Matemática, no así como se apreciara a continuación, en la deserción que se produjo en el segundo año en la cual informaron sobre aspectos relacionados tanto con dicha escuela como con el CIDE.

\section{La deserción en el segundo año de la carrera}

La deserción en el segundo año en las cohortes 2007 y 2009 mostró una evidente falta de motivación académica para continuar en la carrera, algo que Tinto (1993) denomina como disminución del compromiso para seguir con los estudios. En el caso de la cohorte 2008, tanto la deserción producida en el primer año como en el segundo fue provocada básicamente por la falta de vocación por la carrera.

La desmotivación que se revela en la deserción en el segundo año de estudio se asemeja a lo que Tinto (1993) denomina "sentimiento de no remuneración" por el esfuerzo realizado.

Además de la desmotivación, hubo otros factores que se presentaron en ambas cohortes 2007 y 2009. Entre esos factores las situaciones inesperadas y domésticas fueron algunos de los mencionados. Estas circunstancias les provocaron problemas económicos haciendo que optaran por encontrar un empleo y como resultado el tiempo para socializar y estudiar disminuyó. Adicionalmente apareció la dificultad de no poder acomodar convenientemente los horarios ni en la Escuela de Matemática ni el CIDE.

¿Fueron los horarios los culpables de que desertaran? La respuesta es no, pues pese a que sí influyeron en la deserción, antes de que aparecieran las situaciones inesperadas y domésticas que les obligaron a obtener un empleo, otros factores ya habían minado la motivación académica estudiantil.

De esta forma se puede concluir que las expectativas no satisfechas, la falta de estímulos en el hogar, una situación económica mala, las dificultades con algún curso en particular, ya habían disminuido el deseo de continuar en la carrera. Un aspecto importante de resaltar es que este último factor hizo referencia no solo a la Escuela de Matemática sino también al CIDE. 
doi: http://dx.doi.org/10.15359/ree.20-1.5

URL: http://www.una.ac.cr/educare

CORREO: educare@una.cr

Por lo tanto, antes de que apareciera la necesidad de trabajar para sufragar las situaciones inesperadas, la motivación ya no era la misma que en un principio, por lo que, como afirma Tinto (1993), cuando el sentimiento de remuneración es nulo, cualquier evento repentino sirve de excusa para darse por vencido.

Si las expectativas no satisfechas y las dificultades con alguna materia fueron factores involucrados en la deserción, es preciso saber, entonces, qué esperaban de la carrera y a qué se refirieron cuando hablaron de las dificultades que tuvieron.

Los grupos participantes de las cohortes 2007 y 2009, los cuales se marcharon en el segundo año de la carrera, mencionaron que las dificultades con los cursos tuvieron relación con la evaluación realizada en las clases de Currículum y Planeamiento Didáctico impartida por el CIDE y Lógica y Teoría de Conjuntos recibida en la Escuela de Matemática.

Con respecto a Curriculum y Planeamiento Didáctico un participante dijo:

Umm digamos...ehhh la forma de pensar mía no era igual que la del profesor, de la profesora, era más castigar que una forma de evaluar, solo pensar diferente, yo siento que eso no debería ser así (participante de cohorte 2007 II, estudiante de Contaduría y Finanzas).

En relación con Lógica y Teoría de Conjuntos, otro participante narro lo siguiente:

Lógica, pero no es que sea tan difícil, sí me iba ó sea yo fui a las prácticas me iba bien en clases pero en los exámenes por lo general creo que no, en clase me iba muy bien pero al momento que iba hacerlos, ó sea yo podía hacer las prácticas pero al momento que iba hacer el examen hasta ahíllegó todo (participante de cohorte 2009 II, estudiante de Enseñanza de la Matemática).

En lo concerniente a las expectativas no satisfechas, las ideas de participantes que se marcharon durante el segundo año de la carrera difieren de las respuestas que dieron quienes desertaron en el primer año. Pues los que se fueron en el segundo se refirieron al contenido académico de los cursos y, por otra parte, los desertores y desertoras de primer año hicieron referencia al trato que recibían. Lo anterior puede deberse simplemente al hecho de quienes desertaron en el segundo año estuvieron más tiempo cursando la carrera, por lo que llevaron más clases y pudieron hacer comparaciones con su conocimiento previo.

Los cursos sí son muy diferentes a lo que uno ha visto en el colegio, son completamente diferentes... era algo nunca visto ni en el cole ni en ningún lado ... mucha, mucha lógica, era como así mucha práctica, práctica (participante de cohorte 2009 Il, actualmente estudiante de Enseñanza de la Matemática).

Di uno tiene la idea como del colegio, matemática de colegio,... obviamente no porque usan más la lógica (participante de cohorte 2007 II, estudiante de Diseño Publicitario). 


\section{Becas versus un empleo}

Un hecho importante de resaltar fue que la mayor parte de personas entrevistadas que desertaron en el segundo año de la carrera, tenían algún tipo de beca. Esta ayuda, seguida de su motivación inicial por estudiar y terminar la carrera de Enseñanza de la Matemática fueron, quizás, los factores que les mantuvieron hasta el segundo año de estudio; sin embargo, decidieron al final desertar.

\section{¿Por qué ocurrió esto?}

"El tener beca" de acuerdo con el testimonio de los grupos informantes los obligaba a llevar el bloque completo de clases, por lo que si se tenía la obligación de laborar y no se encontraban horarios convenientes en las dos unidades académicas para matricular dicho bloque de clases no se podía mantener la beca. Adicionalmente, manifestaron que dicha ayuda no era significativa, pues a pesar de recibirla se vieron en la necesidad de tener que trabajar para lidiar con las situaciones inesperadas.

Por lo anterior y a diferencia de otros estudios, este artículo encuentra que no fueron, en primera instancia, los problemas económicos los que ocasionaron la deserción, pues antes de que aparecieran, los estudiantes se encontraban ya predispuestos a abandonar la carrera.

... no podía llevar todos los cursos que se podían llevar, tenía que llevarlos por espacios pequeños no más bien por cantidades pequeñas, entonces iba a durar más (participante de cohorte 2007 II, Estudiante de Contaduría y Finanzas).

... primero si uno se queda en un curso hay que esperar al otro año entonces prácticamente estás perdiendo un año, depende del curso eso le abre la malla curricular ahora entonces es como un poco ... complicado seguir (participante de cohorte 2009 II, estudiante de Enseñanza de la Matemática).

En síntesis, la deserción tanto en el primer año como en el segundo reviste causas similares; sin embargo, en el primer año, tomando en consideración la variedad de factores involucrados, la poca integración al rigor de la carrera es evidente. Por el contrario, la deserción en el segundo reviste un importante carácter motivacional. 
doi: http://dx.doi.org/10.15359/ree.20-1.5

URL: http://www.una.ac.cr/educare

CORREO: educare@una.cr

\section{Conclusiones}

1. Al considerar el anterior estudio de Chaves (2003) con respecto a cohortes entre 1995 y 1998 y los promedios de deserción obtenidos durante esta investigación en referencia a las cohortes 2007, 2008 y 2009, la problemática de deserción no ha disminuido considerablemente.

2. En lo que concierne a este estudio, la variable del sexo con respecto a la cantidad de matriculados no determinó necesariamente el sexo en la cantidad de desertores y desertoras, pues en cuanto a los porcentajes de deserción, se encontró que los hombres fueron los mayores desertores aún en la cohorte 2009 en la cual las mujeres presentaron mayores porcentajes de inscripción.

3. En el fenómeno de deserción de la carrera de Enseñanza de la Matemática en referencia a las cohortes 2007, 2008 y 2009 se encuentra involucrada la participación de la Escuela de Matemática y la División de Educología en lo que a factores institucionales se refiere, sobre todo en el segundo año de la carrera en mención.

4. En contraste con otros estudios sobre deserción universitaria, y en lo que respecta a estudiantes participantes en esta investigación, si bien los aspectos socioeconómicos influyeron en alguna medida en el abandono de la carrera en el primer y en el segundo, estos no fueron los de mayor relevancia a diferencia de los factores individuales, académicos e institucionales, los cuales sí presentaron mayor incidencia en el abandono de los estudios.

5. En cuanto a los esfuerzos realizados en 2008 y 2009 para disminuir la deserción, los cuales son consistentes con las modificaciones realizadas a la malla curricular, si bien los índices de deserción entre las cohortes 2007 y 2008 muestran una disminución, la cohorte 2009 de nuevo evidencia porcentajes similares a la cohorte 2007, lo cual significa que la deserción es muy variable y no es un fenómeno que se pueda atacar únicamente con medidas de esta índole, pues como se mencionó en reiteradas ocasiones es un problema relacionado con varios factores, por lo tanto, no se debe asumir que son únicamente los aspectos académicos los que menguaron la problemática, pues en este sentido y de acuerdo únicamente con los parámetros de este estudio, la modificación de la malla curricular parece no haber contribuido a solucionar el problema.

6. La investigación encontró que el malestar sentido por el estudiantado acerca del ambiente donde se desarrollaba la Carrera de Enseñanza de la Matemática influyó directamente en su percepción con respecto al ambiente universitario en toda la UNA, por lo que quienes desertaron por falta de vocación y falta de integración social al entorno donde se desarrollaba la carrera también lo hicieron de la institución para proseguir con sus carreras en otras universidades. 
doi: http://dx.doi.org/10.15359/ree.20-1.5

7. La Carrera de Enseñanza de la Matemática en cuanto a su contenido académico resulta ser una disciplina desconocida para el estudiantado de primer ingreso como quedó demostrado en las expectativas no satisfechas de los grupos participantes.

8. De acuerdo con los resultados de este estudio, la dificultad de la carrera de Enseñanza de la Matemática no solo radica en el rigor académico de la disciplina sino también en su cultura y en el ambiente organizacional donde se desarrolla.

9. El factor motivacional fue uno de los aspectos más importantes en la deserción de la carrera en las cohortes 2007, 2008 y 2009 y estuvo ligado, de acuerdo con el testimonio de las entrevistas, directamente con la actitud del profesorado.

10. Mientras la carrera de Enseñanza de la Matemática no cuente con un examen de admisión o diagnóstico que contemple no solo la capacidad académica que el estudiante traiga consigo de la secundaria, sino también la actitud motivacional así como los intereses, intenciones y algunos antecedentes de la vida del estudiante, la disciplina continuará presentando deserción a causa de la poca integración académica ocasionada por la falta de vocación.

\section{Referencias}

Brenes, M. I. (2005). Deserción y repitencia en educación superior universitaria en Costa Rica (Informe de investigación). San José: Cista Rica: CONARE.

Canales, A. y de los Ríos, D. (Julio, 2007). Factores explicativos de la deserción universitaria. Calidad en la educación, 26, 173-201. Recuperado de http://www.alfaguia.org/alfaguia/ files/1341266791 2599.pdf

Castillo, M. (Abril, 2008).Tasas de deserción en la universidad estatal a distancia de Costa Rica. Actualidades Investigativas en Educación, 8(1), 1-32. Recuperado de http://revista.inie.ucr. ac.cr/index.php/aie/article/viewFile/275/274

Chaves, E. (2003). Graduación y deserción en la escuela de matemática de la UNA: Cohortes 1995 a 1998. Uniciencia, 20(1), 115-122. Recuperado de http://www.fcen.una.ac.cr/uniciencia/ Vol 20 N1\%28Paper 09\%29.pdf

Escuela de Matemática, Universidad Nacional, Costa Rica (Acta No. 15, 2007), oficio FCEN - ACA443-2007.

Ethington, C. A. (Junio, 1990). A psychological model of student persistence [Un modelo psicológico de la persistencia de los estudiantes]. Research in Higher Education, 31(3), 279293. doi: http://dx.doi.org/10.1007/BF00992313 
doi: http://dx.doi.org/10.15359/ree.20-1.5

URL: http://www.una.ac.cr/educare

CORREO: educare@una.cr

Fishbein, M. y Ajzen, I. (1975). Attitudes toward objects as predictors of simple and múltiple behavioural criteria [Las actitudes hacia los objetos como predictores de criterios conductuales simples y multiples. Revisión psicológica]. Psycological Review, 81(1), 59-74. doi: http://dx.doi.org/10.1037/h0035872

Guzmán, C., Durán, D., Gallego, J. F., Castaño, E., Gallón, S., Gómez, K., y Vásquez, J. (2009). Deserción estudiantil en la educación superior colombiana. Bogotá: Ministerio de Educación Nacional. Recuperado de http://www.mineducacion.gov.co/sistemasdeinformacion/1735/ articles-254702 libro desercion.pdf

Hernández, R., Fernández, C., Baptista, P. (2010). Metodología de la investigación. México, D.F.: McGraw-Hill.

Himmel, E. (2005). Modelos de análisis de la deserción estudiantil en la educación superior. Recuperado de http://preu.unillanos.edu.co/sites/default/files/fields/documentos/ modelos\%20de\%20an\%C3\%A1lisis\%20Desercion\%20chile.pdf

Informe de ejecutoria (2007-2008). Escuela de Matemática, Universidad Nacional, Costa Rica.

Lagger, J. M., Donnet, E., Gimenez, A. y Samoluk, M. (2008). La deserción de los alumnos universitarios, sus causas y los factores (pedagógicos, psicopedagógicos, sociales y económicos) que están condicionando el normal desarrollo de la carrera de Ingeniería Industrial, UTN-FRSF. Clubensayos.

Lopera, C. (Julio, 2008). Determinantes de la deserción universitaria en la facultad de Economía de la Universidad del Rosario. Borradores de Investigación, 95, 1-40. Recuperado de http://repository.urosario.edu.co/bitstream/handle/10336/3740/01244396-2008-95-2. pdf? sequence $=2$

Mori, M. (Diciembre, 2012). Deserción universitaria en estudiantes de una universidad privada de Iquitos. Docencia universitaria, 6(1), 60-83. Recuperado de http://www3.upc.edu.pe/ html/0/boletines/ridu/articulo-4-desercion-estudiantil-mori.pdf

Pascarella, E. T. y Terenzini, P. T. (1991). How College Affects Students: Findings and insights from twenty years of research [Cómo afecta a los estudiantes la universidad: Conclusiones y perspectivas de veinte años de investigación]. San Francisco: Jossey-Bass.

Pineda, C. y Pedraza A. (Setiembre-diciembre, 2009). Programas exitosos de retención estudiantil universitaria: Las vivencias de los estudiantes. Revista Virtual Universidad Católica del Norte, 28, 1-30. Recuperado de http://www.redalyc.org/articulo.oa?id=194214468010

Programa Estado de la Nación. (2013). Cuarto informe estado de la educación (Cap. 4. La evolución de la educación superior). San José, Costa Rica: Autor. Recuperado de http://estadonacion. or.cr/files/biblioteca virtual/educacion/004/9-Cap-4.pdf 
doi: http://dx.doi.org/10.15359/ree.20-1.5

URL: http://www.una.ac.cr/educare

CORREO: educare@una.cr

Saldaña, M. y Barriga, O. A. (Octubre-diciembre, 2010). Adaptación del modelo de deserción universitaria de Tinto a la Universidad Católica de la Santísima Concepción, Chile. Revista de Ciencias Sociales, 16(4), 616-628. Recuperado de http://www.redalyc.org/articulo. oa?id=28016613005

Spady, W. G. (1970). Dropouts from higher education: An interdisciplinary review and synthesis [Los abandonos de la educación superior: Una revisión interdisciplinar y síntesis]. Interchange, 1(1), 64-85. doi: http://dx.doi.org/10.1007/BF02214313

Tinto, V. (julio-septiembre, 1989). Definir la deserción: Una cuestión de perspectiva. Revista de la Educación Superior, 18(71), 1-9. Recuperado de http://publicaciones.anuies.mx/pdfs/ revista/Revista71 S1A3ES.pdf

Tinto, V. (1993). Leaving College: Rethinking the Causes and Cures of Student Attrition [Abandonando la universidad; repensando las causas y curas de la deserción estudiantil] ( $2^{\text {a }}$ ed.). Chicago: The University of Chicago Press.

Walz, M. F., Contini, L., Bergesio, A., y Colombini, M. (Agosto, 2009). Factores académicos en la deserción universitaria de una carrera que tiene a la matemática en su currículo. Trabajo presentado en el III congreso internacional de educación: Construcciones y perspectivas. Miradas desde y hacia América Latina. Santa Fe, Argentina. Resumen recuperado de http:// www.unam.edu.ar/2008/educacion/trabajos/Eje 4/367-walz.pdf

\section{Cómo citar este artículo en APA:}

Pascua-Cantarero, P. M. (Enero-abril, 2016). Factores relacionados con la deserción en el primer y segundo año de estudio en la carrera de Enseñanza de la Matemática de la Universidad Nacional de Costa Rica. Revista Electrónica Educare, 20(1), 1-23. doi: http://dx.doi.org/10.15359/ree.20-1.5

Nota: Para citar este artículo en otros sistemas puede consultar el hipervínculo "Como citar el artículo" en la barra derecha de nuestro sitio web: http://www.revistas.una.ac.cr/index.php/EDUCARE/index 